\title{
The Moderating Role of Academic Discipline in Acceptance of Video Technology for Educational Purposes
}

\author{
Judit T. Nagy¹, Mária Bernschütz ${ }^{2 *}$ \\ 1 Department of Sociology, Faculty of Humanities and Social Sciences, Károli Gáspár University of the Reformed Church in \\ Hungary, H-1088 Budapest, Reviczky str. 4., Hungary \\ 2 Department of Management and Business Economics, Faculty of Economic and Social Sciences, Budapest University of \\ Technology and Economics, 1117 Budapest, Magyar tudósok körútja 2., Hungary \\ * Corresponding author, e-mail: bernschutz.maria@gtk.bme.hu
}

Received: 17 November 2020, Accepted: 17 March 2021, Published online: 17 December 2021

\begin{abstract}
This study aims to investigate the role played by academic discipline differences in terms of their influence on the acceptance of video technology being used for educational purposes by higher education students. The research model was based on Technology Acceptance Model in which academic discipline (hard, pure, soft, applied) was involved as a moderator variable.

Data were collected from 240 students using a questionnaire on which the partial least-squares structural equation modelling and the Henseler's multi-group analysis were used to compare differences among academic discipline-groups. In summary, results show that the degree of importance attached to perceived usefulness, perceived ease of use and attitude toward video use when students explain the intensity of their instructional video usage differs between hard/soft, and pure/applied academic disciplines. In the case of hard-pure subjects (e.g. natural sciences) and hard-applied subjects (e.g. engineering or computer science) the intensity of video usage, as a learning resource, is mostly determined by the students' expectations in relation to the effortlessness (or otherwise) of learning with videos. In the case of soft-pure subjects (such as sociology) and soft-applied subjects (such as law and business studies) positive/negative feelings associated with video usage also play an important role in the intensity of video usage as a learning resource. The degree to which a student believes that using videos would enhance his or her learning has a stronger influence on the intensity of video usage in the case of soft-pure subjects than in the case of soft-applied subjects.
\end{abstract}

\section{Keywords}

technology acceptance model, partial least squares - structural equation modelling, multi-group analysis, academic discipline

\section{Introduction}

Video as a web-based multimedia educational device is used in a wider and wider scope in higher education, on the one hand we can thank that to the development of video technology, on the other hand to the development of Internet and multimedia player devices.

Nowadays numerous institutions offer the educational material in video format on the Internet for their students. These are available to the students at any time, and anywhere. Integrating video technology into education is a serious challenge to the institutions and their professors and lecturers, so the assessment of applying educational videos has become inevitable.

Most of the research which has targeted assessment of technology acceptance on the part of students has been based on the Technology Acceptance Model (TAM). This model describes the interrelation among the determining factors of the technology in use. Its usability has been confirmed by numerous studies and it was applied in various samples and fields, including the explanation of using videos (Donkor, 2011; Lee and Lehto, 2013).

The current research was conducted at a university in Hungary where, besides the face-to-face lessons, lecture videos are also available for the students. The research aims to assess those factors which emerge using videos by students and discover the probable differences among the academic disciplines regarding the interrelation of these factors. This kind of analysis on discipline branches has not been typical among studies applying acceptance model. 


\section{Literature review and research model}

\subsection{The Technology Acceptance Model}

The most widely used model for the explanation of students' technology use is the Technology Acceptance Model associated with the name of Davis (1986).

According to the original model, the user attitude has a direct influence on the usage of a new information system, the aim of which is to measure the acceptance on the part of the system user. This attitude toward using is determined by another two variables: perceived usefulness and perceived ease of use.

Later research confirmed that perceived ease of use, beside its effect on attitude, has a direct effect on perceived usefulness as well (Davis et al., 1989; Šumak et al., 2011; Venkatesh and Davis, 2000). The definitions of TAMconstructs are the following: "Attitude refers to the degree of evaluative effect that an individual associates with using the target system in his or her job" (Fishbein and Ajzen (1975) as cited in Davis' (1986:p.25) work).

"Perceived usefulness is defined as the degree to which an individual believes that using a particular system would enhance his or her job performance" (Fishbein and Ajzen (1975) as cited in Davis' (1986:p.26) work).

"Perceived ease of use is defined as the degree to which an individual believes that using a particular system would be free of physical and mental effort." (Fishbein and Ajzen (1975) as cited in Davis' (1986:p.26) work).

Later studies confirmed that perceived usefulness and perceived ease of use affect the model not only indirectly, but also directly (Davis et al., 1989; Šumak et al., 2011; Venkatesh and Davis, 2000) (Fig. 1).

Over the past thirty years, the extent of research based on the model has grown (Scherer and Teo, 2019). With the appearance of technologies that could be transferred to different contexts (Scherer et al., 2019) and thus acquire new uses (such as the Internet, e-mail, digital libraries, electronic commerce, internet banking, on-line learning)

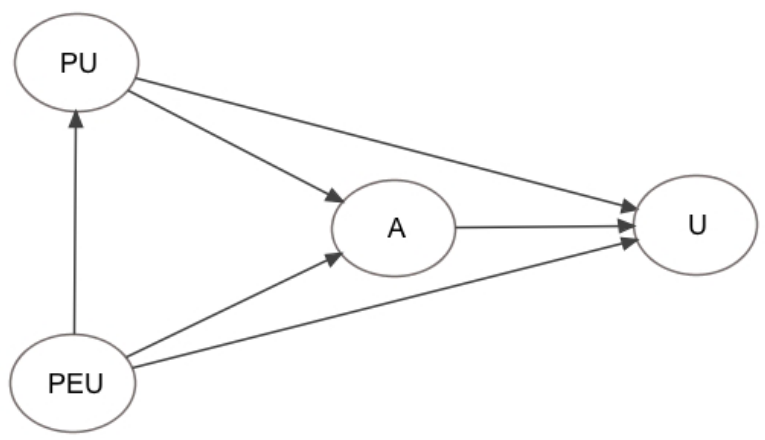

Fig. 1 Correlation of TAM factors (note: PU = Perceived Usefulness; $\mathrm{PEU}=$ Perceived Ease of Use; $\mathrm{A}=$ Attitude; $\mathrm{U}=$ video Usage)
TAM was a key model for examining why people accept or refuse a given technology in a given context (Granić and Marangunić, 2019).

As regards the educational technology research TAM and its extensions have up to now been the most frequently used model (Granić and Marangunić, 2019). It is still viewed as having great potential in acceptance research (Valverde-Berrocoso et al., 2020).

In educational settings the aim is to understand students' behaviour with the help of the model, using any new Information and Communication Technology, with the aim of supporting the process of learning, teaching and assessment.

In the course of its application in Education a wide range of contradictory or inconsistent results occur because TAM has been used in different learning domains, with different learning technologies, and with different types of users (from different cultures) (Granić and Marangunić, 2019; Scherer and Teo, 2019).

To resolve this issue, meta-analysis and systemic reviews of existing research can be used on the one hand; on the other hand, we can compare the results for different learning domains, technologies, or user types by introducing so-called moderator variables.

\subsection{Moderator variables in Technology Acceptance Model}

One part of the recently carried out TAM studies focused on extending the model by further variables (Al-Emran et al., 2018; Murillo et al., 2021; Scherer and Teo, 2019). By involving further variables, the explanatory power of the basic model can be improved. These variables can be placed into four groups (Al-Emran et al., 2018; King and He, 2006):

1. External variables (prior factors), which predict perceived usefulness and perceived ease of use.

2. Mediator variables, which can be created within TAM basic variables, they are generally factors from other theories/models.

3. Moderator variables (Contextual factors), which have controlling / moderating impact on the relations generated among the core TAM-variables.

4. Consequent variables, which appear in the model as a result of the system usage.

In the acceptance model of education research, the most frequently presumed and investigated moderators are gender (Ahmad et al., 2010; Arenas-Gaitán et al., 2010; Kim, 2010; Okazaki and Renda dos Santos, 2012; Ong and 
Lai, 2006; Padilla-Meléndez et al., 2013; Tarhini et al., 2015; Terzis and Economides, 2011; Umrani and Ghadially, 2008; Zogheib et al., 2015); age (Ramírez-Correa et al., 2015; Tarhini et al., 2015), experience (Al-Gahtani, 2016; Alharbi and Drew, 2014; King and He, 2006), user-type (for example undergraduate / graduate students), and technology-type (for example e-learning system / technology / tool) (Pan et al., 2005; Šumak et al., 2011; Yousafzai et al., 2007).

As shown in the previous paragraph, the most frequently applied variables are all individual factors and technological factors. Only one educational acceptance study was found, which investigates the moderator effect of academic discipline. Orji (2010) applied the breakdown of Engineering faculty / Art \& Science faculty / Social Science faculty and concluded that the technology use and technology acceptance of the three groups are different. This indicates that academic discipline is an important moderator variable within the investigation of technology acceptance.

\subsection{The role of academic discipline}

Numerous research results support the theory that academic discipline influences the affective characteristics and the behaviour of people (Elchardus and Spruyt, 2009; Kuo et al., 2014; Mastekaasa, 2005; Postareff et al., 2007; Zakrisson and Ekehammar, 1998).

In this research, the subdivision of academic disciplines by Biglan (1973) was used. It applies four disciplinary quadrants which are determined by two classifications. One dimension is hard/soft which refers to "the degree to which a paradigm exists" (Biglan, 1973:p.202). Hard disciplines have a greater consensus about principles than their soft counterparts. The other dimension is pure/applied which refers to "the degree of concern with application to practical problems" (Biglan, 1973:p.202). Applied disciplines more concerned about applications than pure disciplines.

Based on this the hard-pure quadrant contains for example the natural sciences, while the hard-applied quadrant does engineering and computer science. The soft-applied quadrant includes law and business studies, while the softpure quadrant does sociology.

\subsection{The aim of the research and the subject of the research}

This study focuses on videos used in Higher Education as new resources as applied by the individual for independent educational purposes.

Our aim was to discover whether the core-TAM variables (perceived ease of use, perceived usefulness, and attitude) determine video usage differently in the different areas of academic disciplines. We expected the results to help us make the teaching/learning process more efficient.

The research was carried out between the Spring semesters of 2013/2014 and 2014/2015 among the students of one university. The subjects of the research were the registered students of the above-mentioned semesters who during their course, in addition to traditional classroom teaching, had free access to lecture videos. Thus, video appeared as a new e-learning technology. The videos were chronologically uploaded subject by subject on to the Coospace learning management system (LMS) developed in Hungary. The students could sign into the LMS after identification. Since there were no keywords/tags, special search was not possible; the students could see only the date of the recording and the title of the lecture.

\subsection{Research model}

Based on the aim of the research, a research model was created, shown in Fig. 2. The basic TAM relations: perceived ease of use, perceived usefulness, attitude, and video usage variables were assumed and the effect of academic discipline as a moderator was investigated with regard to the total relations.

In our educational setting the TAM variables can be defined as follows:

- Perceived ease of use is the strength of one's belief that learning with videos would be free of effort. It involves finding the videos within the LMS; finding the video within a subject belonging to a given

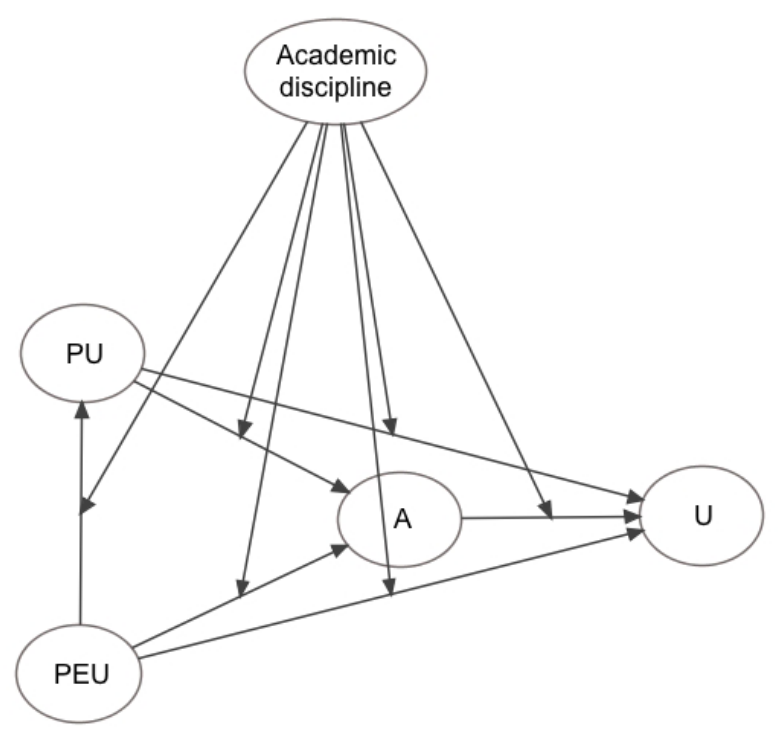

Fig. 2 Research model (note: PU = Perceived Usefulness; $\mathrm{PEU}=$ Perceived Ease of Use; $\mathrm{A}=$ Attitude; $\mathrm{U}=$ video Usage) 
topic; the simplicity of navigation on the student's own equipment within a video and the simplicity of learning with the help of videos.

- Perceived usefulness is the strength of one's belief that using videos will enhance his or her learning, improve his or her learning performance. Usefulness involves the applicability of videos, free from additional work as well as the sufficiency of the contents of the videos for individual learning.

- Attitude is the strength of one's favourable or unfavourable disposition towards video use for learning.

- Video usage is the intensity of using videos as learning resources.

\section{Research method}

\subsection{Data collection method, circumstances of data recording}

Data collection was carried out by self-completed online questionnaire. The questionnaire was sent to the involved students at the end of the 2014/15 semester (7 May 2015) via email. A month later, for increasing the response rate, a reminder email was sent. The questionnaire was available until September 2015 and was completed by 240 students in total.

\subsection{Question groups of questionnaire and content validity}

The questionnaire included three types of question groups. For collecting the demographic and study data multiple-choice questions were used (5 items), from which one numeric- and four nominal-level variables were gained: age (year), gender (male or female), course (daytime or correspondence), academic discipline 1 (hard or soft), academic discipline 2 (pure or applied). The latter two variables identified types of subjects. Video use was measured by a five-point scale. The possible responses varied from "Not at all" (1) to "On a daily basis or more frequently" (5). For measuring the perceived usefulness and perceived ease of use, $3+3$ items of Davis' (1989) scales were applied while attitude was measured by 3 items of Fishbein and Ajzen (1975) (as cited in Davis's (1986:p.93) work).

The indicators providing the content validity were taken from earlier studies, as well as utilised many times since. Thus, the measurement of latent variables was accomplished by the application of reduced versions of widely-used and verified scales.

\subsection{The sample}

The received 240 answers did not include invalid ones thus a 240-element sample was gained, which proved to be able to set a research model.

\subsection{Data analysis technique}

As the first step of the data analysis, the sample was divided into two groups based on the variable values of academic discipline 1, then academic discipline 2. Partial leastsquares (PLS) path analyses were performed on the two sub-samples. The path coefficients were tested by $t$-tests using bootstrap distribution. Following this, the appropriate PLS path coefficients were compared among the academic disciplines by Henseler's PLS multi-group analysis (MGA) method. During the bootstrap sampling, 5,000 generated sub-samples and individual sign changes were applied.

The analysis was carried out using the SmartPLS 3 program (Ringle et al., 2005), which allows the simultaneous set up of PLS-path analysis and PLS-MGA.

\subsection{Outer model examination: reliability and validity}

In order to examine construct reliability, the Cronbachalfa measurement of inner consistency with 0.7 limit was used (Cronbach, 1951) as well as composite reliability (CR) also with 0.7 limit (Werts et al., 1974).

Based on the classification of Henseler et al. (2009), content validity, convergent validity and discriminant validity are examined. The assessment of convergent validity was carried out with the help of average variance extracted (AVE) based on the 0.5 criterion value, suggested by Fornell and Larcker (1981). Discriminant validity was proved with the help of the AVE values based on Fornell and Larcker criterion. Since, in the case of all variables, the square root of AVE values is greater than the off-diagonal values, discriminant validity between variables is satisfactory (Fornell and Larcker, 1981).

\section{Results and discussion}

Fig. 3 presents the results of the structural model and in Table 1 the results of Henseler's MGA, applied to the comparisons of the Academic discipline-specific path coefficients, can be seen.

1 During the modelling the estimate of the path coefficients was performed by path coefficient weighting. The shoutdown condition of the algorithm was reaching 300 iterations or lower factor value change than among the iteration steps. 


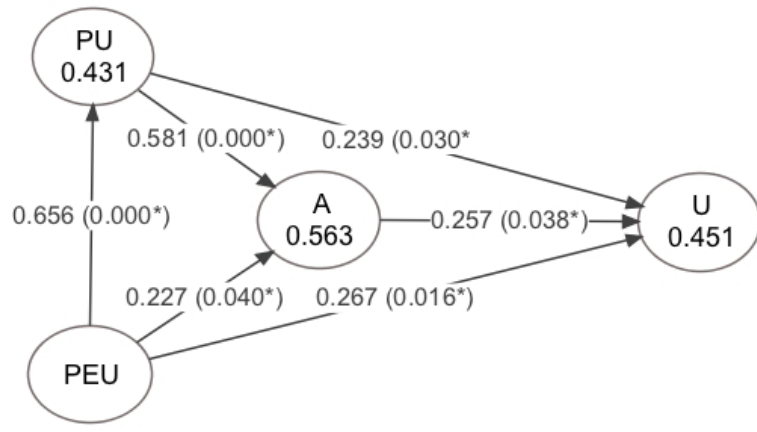

(a)

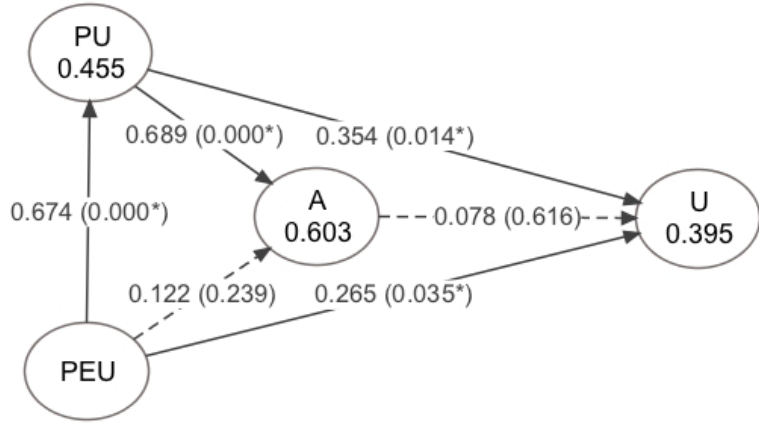

(c)

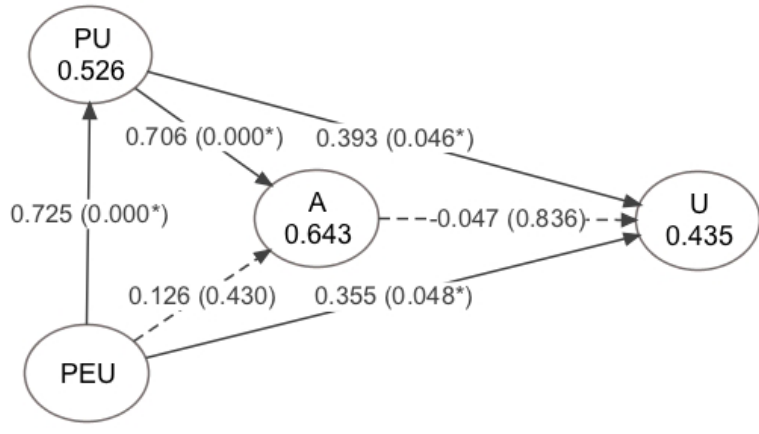

(b)

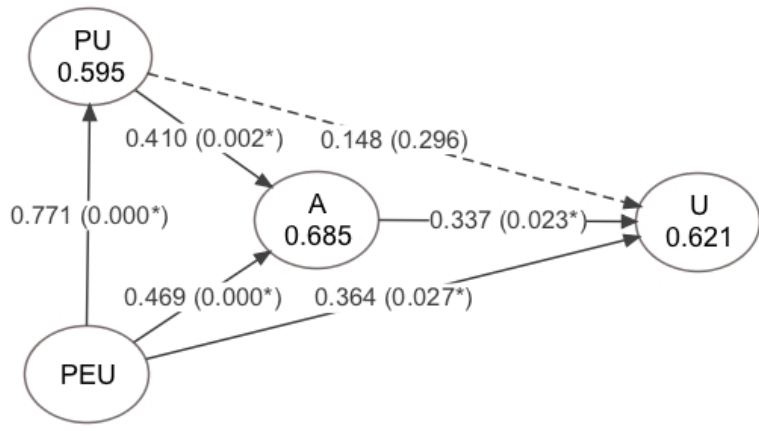

(d)

Fig. 3 PLS results, Academic discipline: (a) hard, (b) soft, (c) pure, (d) applied (notes to Fig. 3 (a)-(d): 1. The explained variance $\left(R^{2}\right)$ is shown in the circles, path coefficient on arrows, bootstrap results in brackets. 2. PU = Perceived Usefulness; PEU = Perceived Ease of Use; $A=A t t i t u d e ; ~ U=$ video Usage 3 . $*$ significant path coefficient at alfa $=0.05$ )

Table 1 PLS-MGA results notes: 1. PU = Perceived Usefulness; PEU $=$ Perceived Ease of Use; $A=$ Attitude; $U$ = video Usage; 2. $*$ significant difference at alfa $=0.05$ )

\begin{tabular}{lcc}
\hline & hard-soft & pure-applied \\
& $p$ & $p$ \\
\hline PEU - PU & 0.786 & 0.888 \\
PEU - A & 0.302 & $0.980^{*}$ \\
PU - A & 0.772 & $0.041^{*}$ \\
A - U & 0.119 & 0.889 \\
PU - U & 0.753 & 0.152 \\
PEU - U & 0.675 & 0.684 \\
\hline
\end{tabular}

In the case of all four groups, moderate explanatory power was achieved in relation to video usage (hard: $R^{2}=0.451$, soft: $R^{2}=0.435$, pure: $R^{2}=0.395$, applied: $\left.R^{2}=0.621\right)$.

On the basis of these results, it can be declared that in case of hard subjects, perceived ease of use is the strongest direct determinant of video usage, $\left(b^{\text {(hard) }}=0.267\right.$, $p=0.016)$, while in case of soft subjects, it is perceived usefulness $\left(b^{\text {(soft) }}=0.393, p=0.046\right)$. In contrast to the hard subjects, in case of soft subjects, the perceived ease of use does not play a significant role in direct influence of attitude ( $\left.b^{\text {(soft) }}=0.126, p=0.430\right)$, furthermore the direct effect of attitude to video usage is not significant, either $\left(b^{\text {(soft) }}=0.047, p=0.836\right)$.
If we compare the path coefficients of groups of pure and applied subjects it can be declared that in case of applied subjects, the perceived ease of use is the strongest direct determinant of video usage $\left(b^{\text {(applied) }}=0.364, p=0.027\right)$, while in case of pure subjects, it is perceived usefulness ( $\left.b^{\text {(pure) }}=0.354, p=0.014\right)$. In the case of pure subjects, the perceived ease of use does not play a significant role in direct influence of attitude $\left(b^{\text {(pure) }}=0.122, p=0.239\right)$, furthermore the direct effect of attitude to video usage is not significant, either $\left(b^{\text {(pure) }}=0.078, p=0.616\right)$. While in case of applied subjects, the perceived usefulness does not play a significant role in explanation of video usage $\left(b^{\text {(applied) }}=0.148, p=0.296\right)$.

The other TAM relations all proved to be significant, but in a single case the difference in path coefficients between the pure and the applied group was noticeable. The direct effect of perceived usefulness to attitude is significantly stronger in case of pure subjects than in case of applied subjects $(p=0.041)$. The students' positive attitude toward video usage in - of pure subjects - video usage is higher than in applied subjects.

Considering the indirect effects (the effect sizes are calculated as the sum products of path coefficients), it is possible to determine which factor plays the most important role in explaining the intensity of video usage. 
In the case of hard subjects - which have high paradigmatic development - the intensity of video use is mostly influenced by how easy and effortless the video usage is for students $(0.267+0.227 \times 0.257+0.656 \times 0.581 \times 0.257$ $+0.656 \times 0.239=0.580$ ), while in the case of soft subjects with lower levels of paradigmatic development - the intensity of video use is mostly influenced by the positive/negative feelings related to the videos.

For both pure and applied subjects (where this dimension measures the degree of concern with application), the intensity of video usage is influencing via how easy and effortless the video usage is for students (pure: $0.265+0.674 \times 0.354+0.674 \times 0.689 \times 0.078$ $+0.122 \times 0.078=0.548)$, applied: $0.364+0.469 \times 0.337$ $+0.771 \times 0.410 \times 0.337+0.771 \times 0.148=0.737)$.

\section{Summary}

The results of the study have numerous consequences regarding the research and practice.

The data partially supports the theory that fundamental TAM interrelations exist with regard to the use of instructional video in the Hungarian higher education environment. The TAM approach has been shown to be robust and to have explanatory power. Between the different disciplinary categories the following differences have been identified: in relation to explanations given for video usage, it was found that those studying hard subjects mentioned perceived ease of use and attitude as mattering most to them, whereas those studying soft subjects mentioned perceived usefulness as playing the most important role.

The results were similar regarding the pure and applied subjects. In explanation of video usage, in case of pure subjects, perceived usefulness, while in case of applied

\section{References}

Ahmad, T. B. T., Madarsha, K. B., Zainuddin, A. M. H., Ismaiel, H. N. A., Nordin, S. M. (2010) "Faculty's acceptance of computer based technology: Cross-validation of an extended model", Australasian Journal of Educational Technology, 26(2), pp. 268-279. https://doi.org/10.14742/ajet.1095

Al-Emran, M., Mezhuyev, V., Kamaludin, A. (2018) "Technology Acceptance Model in M-learning context: A systematic review", Computers \& Education, 125, pp. 389-412. https://doi.org/10.1016/j.compedu.2018.06.008

Al-Gahtani, S. S. (2016) "Empirical investigation of e-learning acceptance and assimilation: A structural equation model", Applied Computing and Informatics, 12(1), pp. 27-50. https://doi.org/10.1016/j.aci.2014.09.001 subjects, perceived ease of use and attitude played more important roles.

Summarising the results received by comparing the disciplinary groups, it can be declared that in the case of hard-pure subjects (e.g. natural sciences) and hard-applied subjects (e.g. engineering or computer science) the intensity of video usage, as a learning resource, is mostly determined by the students' expectations about effortless learning with videos. In case of soft-pure subjects (such as sociology) and soft-applied subjects (such as law and business studies) the positive/negative feelings associated with video usage also play an important role in the intensity of video usage as a learning resource. The degree to which a student believes that using videos would enhance his or her learning has a stronger influence on the intensity of video usage in the case of soft-pure subjects than in the case of soft-applied subjects.

The above results, insofar as they highlight differences in student expectations towards video instruction that correspond to differences in academic disciplines, may contribute to a more effective application of video technology in education in the future.

The significance of the results is currently high according to the period of COVID-19 pandemic, where the universities only offer online courses via information and communications technology, including video technology.

As in every investigation, limitations must be mentioned in relation to the research: these limitations may provide the inspiration for further research. Firstly, since the investigation was carried out among the university students, the generalisation of the results must be performed carefully. Secondly, the explained variance would be increased by extending the model, involving further variables.

Alharbi, S., Drew, S. (2014) "Using the Technology Acceptance Model in Understanding Academics' Behavioural Intention to Use Learning Management Systems", International Journal of Advanced Computer Science and Applications, 5(1), pp. 143-155. https://doi.org/10.14569/IJACSA.2014.050120

Arenas-Gaitán, J., Rondan-Cataluña, F. J., Ramirez-Correa, P. E. (2010) "Gender Influence in Perception and Adoption of E-Learning Platforms", [pdf] In: Advances in Data Networks, Communications, Computers: 9th WSEAS International Conference on Data Networks, Communications, Computers (DNCOCO '10), Faro, Portugal, pp. 30-35. Available at: http://www.wseas.us/e-library/ conferences/2010/Faro/DNCOCO/DNCOCO-04.pdf [Accessed: 12 November 2018] 
Biglan, A. (1973) "The characteristics of subject matter in academic areas", Journal of Applied Psychology, 57(3), pp. 195-203. https://doi.org/10.1037/h0034701

Cronbach, L. J. (1951) "Coefficient alpha and the internal structure of tests", Psychometrika, 16(3), pp. 297-334. https://doi.org/10.1007/BF02310555

Davis, F. D. (1986) "A technology acceptance model for empirically testing new end-user information systems: Theory and results", PhD Thesis, Massachusetts Institute of Technology. Available at: https:// dspace.mit.edu/handle/1721.1/15192 [Accessed: 12 November 2018]

Davis, F. D. (1989) "Perceived Usefulness, Perceived Ease of Use, and User Acceptance of Information Technology", MIS Quarterly, 13(3), pp. 319-340. https://doi.org/10.2307/249008

Davis, F. D., Bagozzi R. P., Warshaw P. R. (1989) "User Acceptance of Computer Technology: A Comparison of Two Theoretical Models", Management Science, 35(8), pp. 903-1028. https://doi.org/10.1287/mnsc.35.8.982

Donkor, F. (2011) "Assessment of learner acceptance and satisfaction with video-based instructional materials for teaching practical skills at a distance", The International Review of Research in Open and Distributed Learning, 12(5), pp. 74-92. https://doi.org/10.19173/irrodl.v12i5.953

Elchardus, M., Spruyt, B. (2009) "The Culture of Academic Disciplines and the Sociopolitical Attitudes of Students: A Test of Selection and Socialization Effects", Social Science Quarterly, 90(2), pp. 446-460. https://doi.org/10.1111/j.1540-6237.2009.00626.x

Fornell, C., Larcker, D. F. (1981) "Evaluating Structural Equation Models with Unobservable Variables and Measurement Error", Journal of Marketing Research, 18(1), pp. 39-50. https://doi.org/10.1177/002224378101800104

Granić, A., Marangunić, N. (2019) "Technology acceptance model in educational context: A systematic literature review", British Journal of Educational Technology, 50(5), pp. 2572-2593. https://doi.org/10.1111/bjet.12864

Henseler, J., Ringle, C. M., Sinkovics, R. R. (2009) "The use of partial least squares path modeling in international marketing", In: Sinkovics, R. R., Ghauri, P. N. (eds.) New Challenges to International Marketing: Advances in International Marketing, Emerald Group Publishing Limited, Bingley, UK, pp. 277-319. https://doi.org/10.1108/S1474-7979(2009)0000020014

Kim, Y-M. (2010) "Gender role and the use of university library website resources: A social cognitive theory perspective", Journal of Information Science, 36(5), pp. 603-617. https://doi.org/10.1177/0165551510377709

King, W. R., He, J. (2006) "A meta-analysis of the technology acceptance model", Information \& Management, 43(6), pp. 740-755. https://doi.org/10.1016/j.im.2006.05.003

Kuo, Y-C., Walker, A. E., Schroder, K. E. E., Belland, B. R. (2014) "Interaction, Internet self-efficacy, and self-regulated learning as predictors of student satisfaction in online education courses", The Internet and Higher Education, 20, pp. 35-50. https://doi.org/10.1016/j.iheduc.2013.10.001

Lee, D. Y., Lehto, M. R. (2013) "User acceptance of YouTube for procedural learning: An extension of the Technology Acceptance Model", Computers \& Education, 61, pp. 193-208. https://doi.org/10.1016/j.compedu.2012.10.001
Mastekaasa, A. (2005) "Gender differences in educational attainment: the case of doctoral degrees in Norway", British Journal of Sociology of Education, 26(3), pp. 375-394. https://doi.org/10.1080/01425690500128908

Murillo, G. G., Novoa-Hernández, P., Rodríguez, R. S. (2021) "Technology Acceptance Model and Moodle: A systematic mapping study", Information Development, 37(4), pp. 617-632. https://doi.org/10.1177/0266666920959367

Okazaki, S., Renda dos Santos L. M. (2012) "Understanding e-learning adoption in Brazil: Major determinants and gender effects", The International Review of Research in Open and Distributed Learning, 13(4), pp. 91-106. https://doi.org/10.19173/irrodl.v13i4.1266

Ong, C.-S., Lai, J.-Y. (2006) "Gender differences in perceptions and relationships among dominants of e-learning acceptance", Computers in Human Behavior, 22(5), pp. 816-829. https://doi.org/10.1016/j.chb.2004.03.006

Orji, R. O. (2010) "Effect of academic discipline on technology acceptance", In: 2010 International Conference on Education and Management Technology, Cairo, Egypt, pp. 617-621. https://doi.org/10.1109/ICEMT.2010.5657581

Padilla-Meléndez, A., del Aguila-Obra, A. R., Garrido-Moreno, A. (2013) "Perceived playfulness, gender differences and technology acceptance model in a blended learning scenario", Computers \& Education, 63, pp. 306-317. https://doi.org/10.1016/j.compedu.2012.12.014

Pan, C-C., Sivo, S., Gunter, G., Cornell, R. (2005) "Students' Perceived Ease of Use of an E-Learning Management System: An Exogenous or Endogenous Variable?", Journal of Educational Computing Research, 33(3), pp. 285-307. https://doi.org/10.2190/7M4G-R742-W9FT-JX1J

Postareff, L., Lindblom-Ylänne, S., Nevgi, A. (2007) "The effect of pedagogical training on teaching in higher education", Teaching and Teacher Education, 23(5), pp. 557-571. https://doi.org/10.1016/j.tate.2006.11.013

Ramírez-Correa, P. E, Arenas-Gaitán J, Rondán-Cataluña F. J. (2015) "Gender and Acceptance of E-Learning: A Multi-Group Analysis Based on a Structural Equation Model among College Students in Chile and Spain", PLoS ONE, 10(10), Article number: e0140460. https://doi.org/10.1371/journal.pone.0140460

Ringle, C. M., Wende, S., Will, A. (2005) "Smartpls, (3.0)", [computer program] Available at: https://www.smartpls.com/ [Accessed: 01 August 2016]

Scherer, R., Siddiq, F., Tondeur, J. (2019) "The technology acceptance model (TAM): A meta-analytic structural equation modeling approach to explaining teachers' adoption of digital technology in education", Computers \& Education, 128, pp. 13-35. https://doi.org/10.1016/j.compedu.2018.09.009

Scherer R., Teo T. (2019) "Editorial to the special section-Technology acceptance models: What we know and what we (still) do not know", British Journal of Educational Technology, 50(5), pp. 2387-2393. https://doi.org/10.1111/bjet.12866

Šumak, B., Heričko, M., Pušnik, M. (2011) "A meta-analysis of e-learning technology acceptance: The role of user types and e-learning technology types", Computers in Human Behavior, 27(6), pp. 2067-2077. https://doi.org/10.1016/j.chb.2011.08.005 
Tarhini, A., Hone, K., Liu, X. (2015) "A cross-cultural examination of the impact of social, organisational and individual factors on educational technology acceptance between British and Lebanese university students", British Journal of Educational Technology, 46(4), pp. 739-755. https://doi.org/10.1111/bjet.12169

Terzis, V., Economides, A. A. (2011) "Computer based assessment: Gender differences in perceptions and acceptance", Computers in Human Behavior, 27(6), pp. 2108-2122. https://doi.org/10.1016/j.chb.2011.06.005

Umrani, F., Ghadially, R. (2008) "Gender and Decision-Making in Technology Adoption among Youth: A Study of Computer Learners in India", Psychology and Developing Societies, 20(2), pp. 209-227. https://doi.org/10.1177/097133360802000204

Valverde-Berrocoso, J., del Carmen Garrido-Arroyo, M., BurgosVidela, C., Morales-Cevallos, M. B. (2020) "Trends in Educational Research about e-Learning: A Systematic Literature Review (2009-2018)", Sustainability, 12(12), Article number: 5153. https://doi.org/10.3390/su12125153

Venkatesh, V., Davis, F. D. (2000) "A Theoretical Extension of the Technology Acceptance Model: Four Longitudinal Field Studies", Management Science, 46(2), pp. 169-332.

https://doi.org/10.1287/mnsc.46.2.186.11926
Werts, C. E., Linn, R. L., Jöreskog. K. G. (1974) "Intraclass Reliability Estimates: Testing Structural Assumptions", Educational and Psychological Measurement, 34(1), pp. 25-33. https://doi.org/10.1177/001316447403400104

Yousafzai, S. Y., Foxall, G. R., Pallister, J. G. (2007) "Technology acceptance: a meta-analysis of the TAM: Part 1", Journal of Modelling in Management, 2(3), pp. 251-280.

https://doi.org/10.1108/17465660710834453

Zakrisson, I., Ekehammar, B. (1998) "Social attitudes and education: Self-selection or socialization?", Scandinavian Journal of Psychology, 39(2), pp. 117-122. https://doi.org/10.1111/1467-9450.00064

Zogheib, B., Rabaa'I, A., Zogheib, S., El Saheli, A. (2015) "University Students' Acceptance of Technology in Math Classes: Does Gender Matter?", Journal of Emerging Trends in Engineering and Applied Sciences, 6(4), pp. 273-287. [online] Available at: https://www. academia.edu/33427330/University_Students_Acceptance_of_ Technology_in_Math_Classes_Does_Gender_Matter[Accessed: 12 November 2018] 